\title{
SUNTINGAN NASKAH MURWAKALA
}

\author{
Siti Masitoh
}

Email: simasan_68@yahoo.com

Fakultas Humaniora dan Budaya Universitas Islam Negeri Maulana Malik Ibrahim Malang

Alamat Koresponden: Jalan Gajayana 50 Malang 65144

\begin{abstract}
Murwakala is the story of the puppet show that is usually used in the Javanesse traditional seremonial namely ruwatan. Since it is oral tradition, it should be changed into the written text when it is analyzed further through the phylological process. The main process in philological activities is determining the most reliable text form. For this purpose, it is necessary to understand particular knowledge on the author, culture and tradition that have influence on the work. This is due to the fact that the main task of philology is criticism towards text and the purpose of the text criticism is the text that is the closest version to the original text. It should be done because usually every story teller has his own style in telling the story, that leads to the variations. In order to get the story which has the best quality, the textual comparation should be done. This article presents those process to get the best written text.
\end{abstract}

\section{Keywords}

Murwakala, Filologi, Ruwatan

\section{Pendahuluan.}

Murwakala adalah judul cerita yang biasanya dilakonkan pada upacara ruwatan. Sebagai sastra lisan cerita ini mempunyai formula tertentu yaitu kelompok kata yang secara teratur digunakan dalam kondisi matra yang sama untuk mengungkapkan ide tertentu yang hakiki.

Formula cerita mengungkapkan empat ide yaitu: (a) nama aktor atau tokoh, dalam Murwakala tokohnya adalah Bathara Guru, Sang Hyang Wisnu, Brahma, Narada, Indra, Kala, Sang Hyang Antaga, Bathari Durgo, mbok Rondo, dan Jatusmati, (b) kejadian utama dalam Murwakala peristiwa yang penting adalah ketika terjadi perang argumentasi antara Dalang Kanda Buwana dengan Bathara Kala. Dalang Kanda Buwana dapat menjelaskan segala rahasia Bethara Kala, asal mulanya (terjadinya) sampai pada perjalanan hidupnya. Sesudah mengakui keunggulan Dalang Kanda Buwana maka Bethara Kala minta kepada Ki Dalang agar membaca tulisan yang terdapat dibadannya. Setelah Dalang Kanda Buwana dapat membaca semua huruf yang tertulis dibadannya, maka Kala minta supaya diruwat oleh Dalang Kanda Buwana. Sebelum permintaannya dikabulkan, Dalang meminta bukti bahwa Kala sungguh - sungguh ikhlas untuk diruwat. Sebagai buktinya Kala memilih sajen kain mori putih, untuk membuktikan bahwa ia tulus dan ikhlas diruwat sehingga dapat kembali pada kesucian lagi, (c) perangkat formula yang mengindikasikan waktu, dalam Murwakala dapat dilihat saat terjadinya Kama Salah ketika Bathara Guru sedang bercengkrama di tamansari waktu itu tepat waktu senja kala (menjelang matahari terbenam) tiba tiba tergugahlah hasrat rasa asmara Bathara Guru kepada Dewi Uma. Namun Dewi Uma menolak keinginan Bathara Guru itu maka jatuhlah sperma Bathara Guru ke dalam laut dan menjadi Kama Salah yang disebut Sang Kendhang Gumulung, dan (d) perangkat formula yang mengindikasikan tempat. Dalam Murwakala banyak kita temui formula yang mengindikasikan tempat, contoh sederhana terjadi pada Bathari Durgo yang diusir oleh Guru dan disuruh pergi ke Nusakambangan menjadi istri Kala.

Bentuk sastra lisan ini harus diubah menjadi bentuk naskah tertulis jika akan diteliti lebih lanjut. Dalam sastra lisan, biasanya pencerita belajar cerita dengan cara menyantrik kemudian menghafal dan menceriterakan kembali sesuai gayanya sendiri. Hal inilah yang menyebabkan terjadinya varian.

Untuk mendapatkan teks dengan kualitas terbaik, penulis harus melakukan perbandingan teks. Mengacu pada fenomena ini, maka tulisan ini dilakukan untuk menjawab pertanyaan: Bagaimanakah proses penyuntingan naskah yang bersumber dari sastra lisan itu dilakukan? 


\section{Penutup}

Adegan pertama terjadi di Kahyangan Suralaya dimana terjadi pertemuan antara Batara Guru dan Batara Narada. Batara Guru menanyakan penyebab terjadinya kekacauan di Madyapada. Ternyata kekacauan itu disebabkan oleh Batara Kala yang memburu orang-orang Sukerta yang akan datang melihat pertunjukkan wayang yang diselenggarakan oleh Prabu Sri Maha Punggung. Pertunjukkan wayang tersebut adalah ruwatan sedekah bumi yang dimaksudkan untuk memohon keselamatan kepada Sang Pencipta dari segala bencana. Tidak beberapa lama kemudian, Batara Kala datang menghadap Batara Guru untuk meminta informasi tentang macam-macam orang Sukerta yang boleh ia makan.

Batara Guru menjelaskan bahwa ada beberapa sumber yang menyebutkan macam-macam orang Sukerta, misalnya surat Centini menyebutkan 146 yang dibagi menjadi Sukerta besar, tengah, dan kecil. Sumber lain yaitu surat Amurwakala yang menyebutkan ada 136 yang dibagi menjadi sukerta besar, tengah, dan kecil tetapi kalau menurut pedoman pedalangan ada 25 yang umum dipakai. Ke-25 macam itu adalah: ontang-anting, ontanganting tunggak aren atau ontang-anting papar tunggak, kedono-kedini, kembang sepasang, ugeruger lawang, sendang kaapit pancuran, gotong mayit, cukit dulit, srimpi, sarombo, kempat kidang, pandowo, ponco putri atau pendawi, banteng ngirit Jawi, Jawi ngirit banteng, jurung pujud, julung kembang, julung caplok, bocah yatim, lungse, dangkal, durgo ngerik, dan kolo kinantang, dia boleh makan orang-orang Sukerta tersebut kecuali orang yang bisa membaca tulisan yang ada di dahi, tenggorokan, dada sampai punggung Batara Kala karena mereka itu kalau bukan bapaknya ya saudara tua Batara Kala sendiri. Melihat begitu banyaknya orang yang bisa menjadi mangsa Batara Kala, Batara Narada memohon kepada Batara Guru untuk mengurangi jumlah kelompok sukerta.

Adegan kedua terjadi ketika Batara Narada meminta Batara Bayu untuk menghalangi keinginan Batara Kala yang ingin memakan orang sukerta. Kemudian Batara Narada menemui Batara Wisnu dan Batara Brama untuk diajak ke Ngarcapada.

Adegan ketiga ditandai dengan adanya pertemuan antara Batara Kala dengan Bapa Tuna. Batara Kala menanyakan arti nama Bapa Tuna. Dia diberi nama Bapa Tuna karena ketika dia dilahirkan sudah tidak ditunggui oleh bapaknya dengan kata lain, dia adalah anak yatim yang juga termasuk dalam kelompok sukerta. Mengetahui Tuna Bapa seorang yatim, Batara Kala bermaksud untuk memangsanya dan Bapa Tuna menolak lalu mengadakan perlawanan sehingga terjadilah perkelaian yang mengakibatkan kekalahan Batara Kala. Dengan tunggang langgang Batara Kala melarikan diri yang kemudian bertemu dengan seorang yang bernama Tuna Bapa. Ketika Batara Kala mengemukan niatnya untuk memangsanya, Bapa Tuna menanyakan, "Apakah Batara Kala bisa menghidupkan orang mati kok berani-beraninya membunuh orang?". Lama kelamaan, Batara Kala menyadari bahwa Tuna Bapa adalah orang yang sama yang pernah dia temui sebelumnya sehingga Batara Kala meninggalkannya.

Adegan keempat terjadi ketika Batara Narada menemui Batara Wisnu dan Batara Brama untuk diajak bersama-sama mencegah keinginan Batara Kala memakan orang sukerta. Usaha itu dilakukan melalui beberapa tahap. Tahap pertama sebelum menata orang lain harus bisa menata hatinya sendiri, kemudian baru menata keluarganya yaitu anak dan istri. Kalau sudah bisa menata keluarga dengan baik baru bisa menata sesama misalnya kelompok atau partai baru kemudian menata dunia. Mereka sepakat untuk pergi ke Ngarcapada. Batara Wisnu menyamar sebagai Dalang Kanda Buwana, Batara Brama menyamar menjadi seorang penggender dan Batara Narada sebagai tukang kendang. Sebelum berangkat, Batara Wisnu bertanya masalah sesajen yang dimaksudkan sebagai tanda berterima kasih kepada Tuhan atas hasil bumi yang telah diberikan. Dalam penyamarannya, Batara Wisnu menggunakan nama "Dalang Kanda Buwana", Batara Brama menggunakan nama "Nyai Seruni" dan Batara Narada menggunakan nama "Kyai Panjak Tapa Wangkeng" atau "Panjak Encek-Enggel".

Adegan kelima terjadi di negara Purma Carita dimana Prabu Sri Maha Punggung bertemu denga Patih Jaka Puring. Prabu Sri Maha Punggung memberitahukan kepada Jaka Puring bahwa dia telah menyuruh Jagabaya mencari seorang dalang pengruwat. Tidak lama kemudian, Dalang Kanda Buwana beserta rombongan menghadap Prabu Sri Maha Panggung. Kemudian Prabu Sri menyerahkan pelaksanaan upacara sedekah bumi kepada dalang Kanda Buwana. Si dalang Kanda Buwana mulai melantunkan kidung pangruwatan. Namun tidak lama kemudian, Batara Kala yang bermaksud menghentikan pertunjukkan wayang datang, tetapi niatnya itu tidak berhasil. Batara Kala bertanya, "Apakah di antara orang yang datang melihat pertunjukkan wayang ada yang tergolong dalam kelompok sukerta?". Jika ada, dia berkehendak untuk memangsanya. Mendengar pertanyaan itu, Dalang Kanda Buwana melarang Batara Kala memangsa orang Sukerta tetapi mempersilahkan untuk memakan si dalang. Alasannya, karena berkumpulnya penonton itu didatangkan oleh si dalang. Oleh sebab itu, yang pantas dimangsa 
Batara Kala adalah dalangnya bukan penontonnya. Batara Kala setuju. Sebelum memangsa si dalang, Batara Kala bertanya, "Apakah dalang bisa membaca tulisan yang ada di dahi, tenggorokan, dada sampai punggung Batara Kala?" Setelah Dalang Kanda Buwana berhasil membaca dan mengartikan semua tulisan yang ada d idahi, tenggorokan, dada dan punggung Batara Kala dengan benar, akhirnya Batara Kala mengakui kehebatan si Dalang Kanda Buwana dan dia berjanji untuk tidak memangsa orang Sukerta lagi kemudian meninggalkan Negara Purwa Carita.

\section{DAFTAR PUSTAKA}

Danandjaja, James. 1994. Folklor Indonesia: Ilmu Gosip, Dongeng dan Lain-lain. Cetakan IV. Jakarta : PT Pustaka Utama Grafiti.

Finnegan,Ruth.1992. Oral Poetry. Bloomington and Indianapolis : First Midland Book Edition.

Kridalaksana, Harimurti. 1993. Kamus Linguistik. Jakarta: Gramedia Pustaka Utama.

Lord, A.B. 1960. The Singer of Tales. Cambridge, Mass: Harvard University Press.

Pamungkas, Ragil. 2008. Tradisi Ruwatan : Misteri di Balik Ruwatan. Yogyakarta: Penerbit NARASI.

Ras ,J.J. 1971. Seminar Filologie. Proyek Linguis. Leiden

2008. Metodologi Kajian Tradisi Lisan. Jakarta: Asosiasi Tradisi Lisan.

Soetarno. 1995. Ruwatan di Daerah Surakarta. Surakarta: CV. Cendrawasih.

Soetomo, Dr. 1995. Ruwatan di Daerah Surakarta. Surakarta: CV. Cendrawasih.

Subalidinata. At.al. 1985. Sejarah dan Perkembangan Cerita Murwakala dan Ruwatan dari Sumber-sumber Sastra Jawa. Yogyakarta: Departemen Pendidikan dan Kebudayaan. Direktorat Jendral Kebudayaan.

Vanoye, Francis. 1973. Expression Communication. Paris: Armand Colin.

Zahra Yudiafi, Siti dan Mu'jizah. 2001. Filologi. Jakarta: Pusat Penerbitan Universitas Terbuka. 